\title{
Estimation of Deformation Modulus of Soil in Field from Laboratory Tests
}

\author{
Yeowon Yoon ${ }^{1}$, Jungho Ki², Ki-il Song ${ }^{1}$ \\ ${ }^{1}$ Inha University \\ Inha-ro 100, Nam-gu, Incheon, Korea \\ Yoonyw@inha.ac.kr; Ksong@inha.ac.kr \\ ${ }^{2}$ Seohyun Engineering \\ Heungandae-ro 500, Anyang, Korea \\ Dizzylover@naver.com
}

\section{Extended Abstract}

Before field test, evaluation of deformation characteristics in laboratory are useful as [2]. For quality evaluation of sub-grade soil of high speed railway track, ratio of deformation modulus between second loading cycle and first loading cycle within certain limit based on plate load tests are required. In order to know the deformation and strength characteristics of soil by the plate load test in advance, simplified relationships using laboratory-based tests are presented.

In this study plate load tests from small size to large size $(2,000 \mathrm{~mm} \times 2,000 \mathrm{~mm} \times 1,200 \mathrm{~mm})$ varying the $\mathrm{ratio}(\mathrm{D} / \mathrm{B})$ of chamber size(D) to plate size(B) were performed to estimate the quality of sub-grade soil by laboratory test. The plate load tests were carried out following DIN 18134 based on [1] currently using in field on sandy soil for different ratio of D/B and deformation moduli, $\mathrm{E}_{\mathrm{v}}$, were obtained. The deformation moduli from small size tests were compared to that from large chamber tests where boundary influence can be neglected.

In order to estimate deformation modulus from the small size plate load tests, the ratio of strain modulus, $\mathrm{E}_{\mathrm{v} 2}$, of second loading cycle to that of first loading cycle, $E_{\mathrm{v} 1}$, were presented as $\mathrm{E}_{\mathrm{v} 2} / \mathrm{E}_{\mathrm{v} 1}=5.39 \log (\mathrm{D} / \mathrm{B})+1.68$. Using this relationship, test results in laboratory small-scale test can be used for the estimation of deformation modulus ratio in field.

\section{References}

[1] Deutsches Institut für Normung DIN 18134, "Determining the deformation and strength characteristics of soil by the plate loading test," 2001.

[2] F. Tatsuoka and S. Shibuya, "Deformation Characteristics of Soils and Rocks from Field and Laboratory Tests," Keynote Lecture for Session no. 1, the 9th Asian Regional Conference on Soil Mechanics and Foundation Engineering, Bangkok, pp. 101-170, 1992. 